\title{
Optimization of Bucket Tooth Excavator Design using Topology Optimization and Finite Element Method
}

\author{
Sumar Hadi Suryo, Rachmat Suryadi Sastra *, Muchammad, Harto \\ Mechanical Engineering Department, Faculty of Engineering, Universitas Diponegoro, Semarang 50275, \\ Indonesia \\ * Corresponding author: rachmatss@ student.undip.ac.id
}

\begin{abstract}
This research discusses the optimization design of bucket tooth on the market to produce a lighter design but still maintains its strength, the type of bucket tooth is Verona PC200.

Methodology: The optimization process in a bucket tooth applies the concept of topology optimization. A static linear analysis was performed by using the finite element analysis to examine the stress values in the structure of bucket tooth. Then the method is determining the design variable of bucket tooth with applied a manufacturing constraint. Optimization gives the new design.

Result: The maximum Von Mises value is $403.81 \mathrm{MPa}$. After that topology optimization is done by selecting several variations of the design area which results in a reduction in mass in first variation of $0.72 \mathrm{~kg}$ and the second variation $1.49 \mathrm{~kg}$. The mass reduction causes a change in stress that occurs in the bucket tooth to $451.8 \mathrm{MPa}$ in first variation and 458.6 $\mathrm{MPa}$ in variation 2, but the stress is still in a safe condition.

Value: Optimization of bucket tooth design in this paper can reduce the cost of production for bucket tooth with considering to keep the strength of bucket tooth.
\end{abstract}

Key words: Bucket tooth design, Topology optimization concept, Reduce cost production, Verona PC200

\section{INTRODUCTION}

Bucket tooth is one important part of the excavator because it has a major role during the process of penetration or excavation [1]. This section often experiences direct contact with different excavation fields. Bucket teeth must have strong, hard, and wear-resistant mechanical properties. However, despite its nature, a bucket tooth needs to be changed when working hours are already due. The frequent replacement contributes to the high maintenance costs [2]. The authors do design optimization on bucket teeth that are already on the market to produce a lighter design, to reduce the content of bucket tooth material that is wasted due to turnover time. In this analysis the design uses a market-based approach from the original design.

For the material properties to be inputted in the simulation, the authors assumed that the bucket tooth material was made of AISI 4140. In this simulation, the static linear method was used for the optimization process.

The optimisation done is optimisation of the topology. The main purpose of the topology optimization was to reduce the volume of the design variable determined by maximizing the stiffness value of the existing model. [3,4]. The objective function of topology optimization is the value of the linear function of the displacement. This function is called compliance, which is an inverse of the rigidity value. The maximum stiffness value can be determined when the minimum compliance value has been reached [5]. Finite element analysis for structural analysis are widely used. Some are them are reported and documented [6-8].

\section{MATERIAL AND RESEARCH METHOD}

\subsection{Material Identification}

In this study, the bucket tooth material used AISI 4140 (see Table 1). The data obtained from this research is required in the optimization process of bucket tooth design this time.

Table 1: AISI 4140 material properties.

\begin{tabular}{|c|l|c|}
\hline No & \multicolumn{1}{|c|}{ Properties } & Value \\
\hline 1 & Modulus of Elasticity E & $205 \mathrm{GPa}$ \\
\hline 2 & Poisson Ratio & 0.29 \\
\hline 3 & Density & $7850 \mathrm{~kg} / \mathrm{m}^{3}$ \\
\hline 4 & Yield Strength & $1515 \mathrm{MPa}$ \\
\hline
\end{tabular}

\subsection{Flow Chart}

In this study there are steps in static linear simulation and bucket tooth optimization which refer to the flow diagram of Figure 1. 


\subsection{Modelling of Bucket Tooth}

The bucket tooth used in this study was the Verona PC200 type bucket tooth as shown in Figure 2 (a). Making bucket tooth design using CAD software using an approach from the original design. In Figure 2 (b) we get the 3D bucket tooth design. The CAD software used to model is Solidworks 2016.

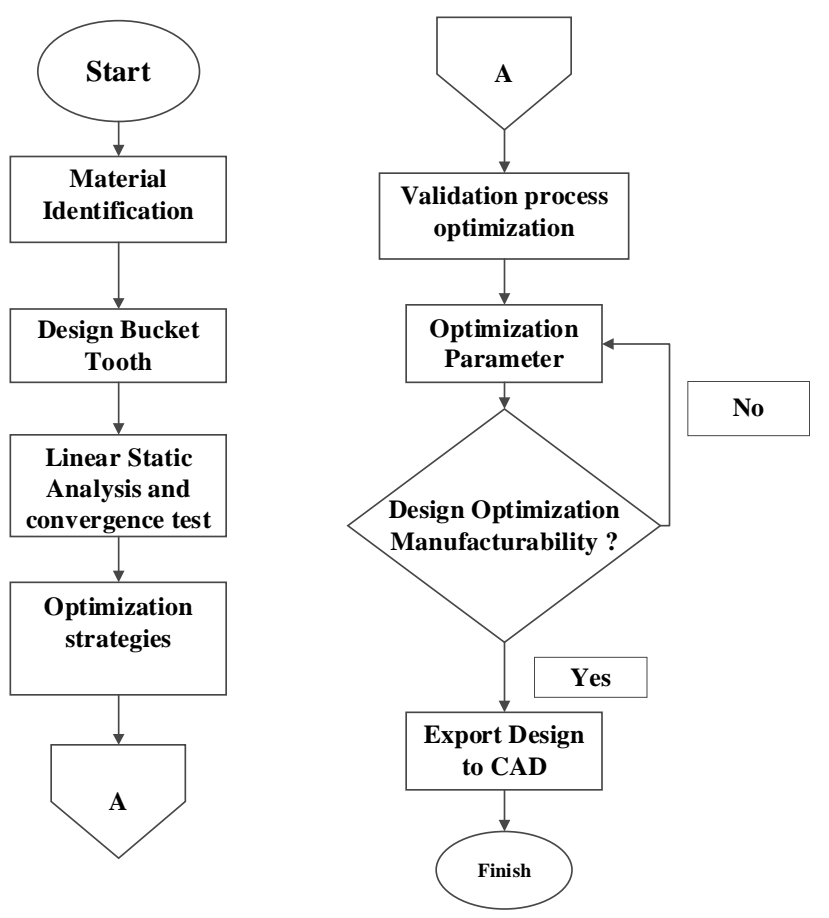

Figure 1: Flow chart

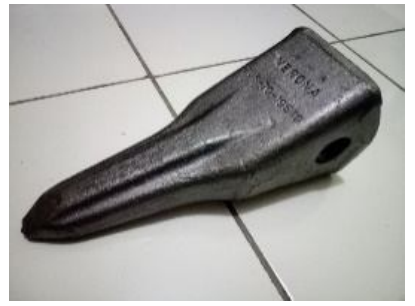

(a)

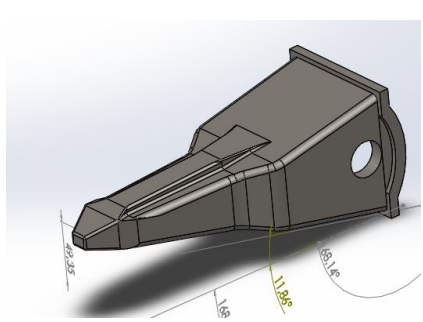

(b)
Figure 2: Bucket tooth design, (a) Original Verona PC200, (b) 3D CAD

\subsection{Linear Static Modelling and Convergence Test}

Static linear modeling is influenced by a force acting on the bucket tooth [9]. In this study, the force obtained from the bucket curling force $(\mathrm{Fb})$ on the Komatsu PC200 excavator was $157000 \mathrm{~N}$. tooth. For maximum conditions, the force occurs at an angle of 32 degrees to the bucket tooth, giving rise to the direction of the force as shown in Figure 3.

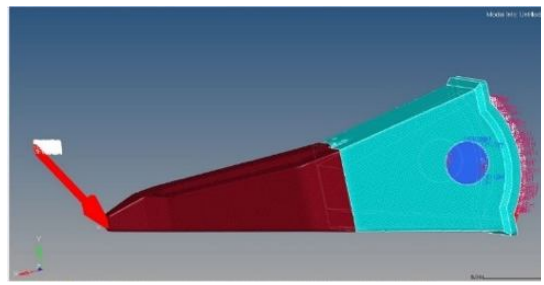

Figure 3: Bucket Curling Force in Linear Static Modelling

\subsection{Optimization Process}

The optimization method used in topology optimization using Altair optistruct software. Topology optimization in bucket tooth design is done because its shape is a three dimensional continuum structure. Topology optimisation may results in a significant mass reduction. The following are the steps to determine the topology optimization strategy:

\section{A. Determine the Design Variable}

The design variable is set to decide what part of the design can be optimally modified. Two variations in the design variable are tried in this work. The comparison of the two variation models are shown in Figure 4. The blue color indicates the design variable while the red color shows the non-design variables or areas that cannot be changed.

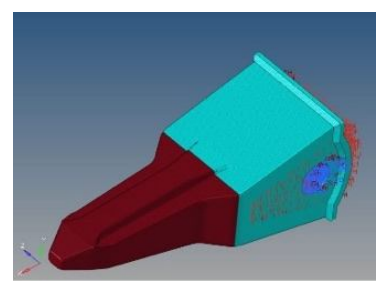

(a)

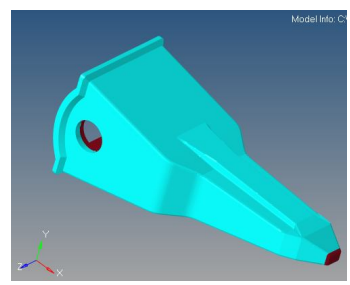

(b)
Figure 4: Variable design 1 (a); Variable design 2 (b)

\section{B. Determine the Constraint}

Design constraints are related to the expected response so that optimisation results can be accepted. The design constraint in the form of a 70 per cent volume fraction.

\section{Determine the Structure Response}

The response is to calculate the performance of the system, which we determine according to the constraints and objectives of what we will determine. The responses used in this optimisation process are weight compliance and volume fraction.

\section{Determine the Objective}

The objective is to optimize each response function, the response is a design variable. The objective of this optimization is to minimize the weight.

\section{E. Determine the Manufacturing Constraint}

The topology optimisation concerns that the design concepts often generated can not be created. Optistruct offers several different methods to take into account manufacturing 
capabilities when performing topology optimization [5]. Therefore, production constraints must be determined in such a way that the results of the optimisation can be produced by determining the results of the optimisation.

\section{Minimum member size control}

Minimum member size control is used to determine the smallest dimensions that must be maintained in topology design. In this study, the minimum value of member size control is determined at $0.16 \mathrm{~mm}$.

\section{Draw Direction}

Drawing direction is used to get the right design when casting. Cavities that are not opened in the process and are not allowed in the direction of the sliding direction of the die.

\section{Pattern Grouping}

Pattern grouping is a feature that determines one part of the domain that must be designed following a particular pattern. This can be applied, for example, to obtain a symmetrical design even if the applied load is not symmetrical. In this study, symmetry pattern grouping is used

\section{RESULT AND DISCUSSION}

\subsection{Result of Linear Static Simulation}

To assess if the material used is not failing and can be improved, a static linear analysis is carried out to obtain the design value of Von Mises with the information obtained from the results[10].

Figure 5 shows results of the linear static analysis. The generated Von Mises value is $403.39 \mathrm{MPa}$, based on the results of the static linear simulation.

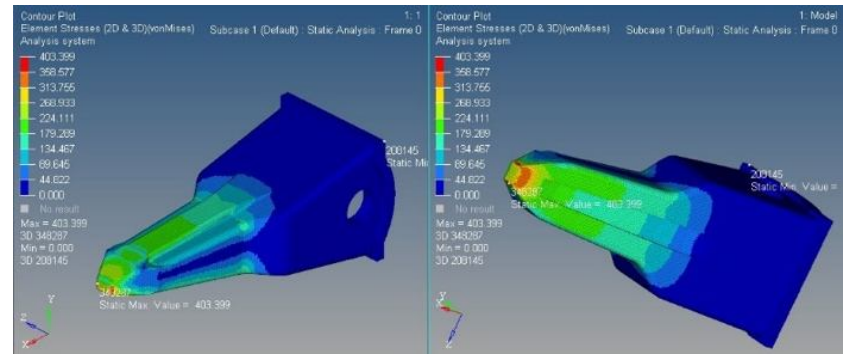

Figure 5: Von Mises Stress of bucket tooth

\subsection{Result of Convergent Test}

To determine the appropriate number of elements to be continued with the optimization process, a convergence test is performed first which can be seen in Table 2 until a convergent result is obtained for each increment of the element by making improvements to the mesh gradually and in certain areas [11].
Table 2: Von Mises maximum stress value for each element.

\begin{tabular}{|c|c|c|}
\hline No & Maximum Stress (MPa) & Element No \\
\hline 1 & 385.798 & 137181 \\
\hline 2 & 400.047 & 144937 \\
\hline 3 & 407.501 & 151890 \\
\hline 4 & 403.968 & 429426 \\
\hline 5 & 403.309 & 447866 \\
\hline
\end{tabular}

Based on the variation of the increment in the elements in Table 2 above, the more the element increases the stress that occurs remains the same, so it can be concluded that the elements show that it is converging. In this study, using the most elements in the 5th convergence test results, namely 447,886 . The stress distribution that occurs in the bucket tooth was show in Figure 6 to Figure 10.

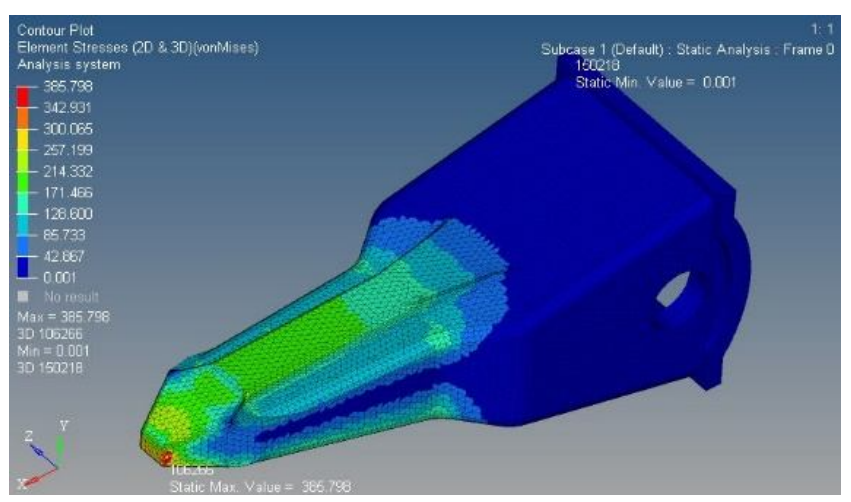

Figure 6: Von Mises value of convergent test 1.

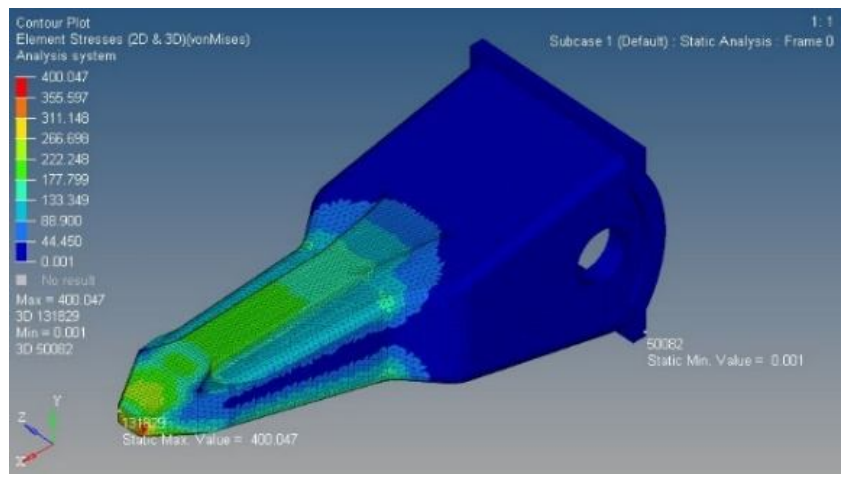

Figure 7: Von Mises value of convergent test 2.

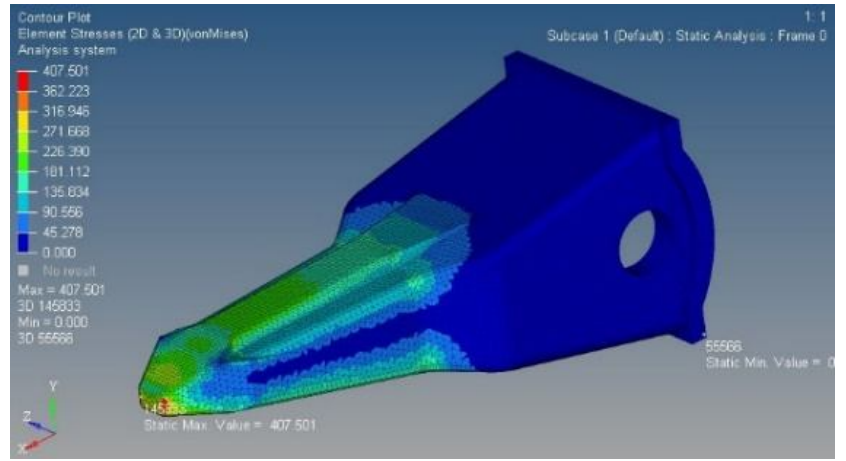

Figure 8: Von Mises value of convergent test 3. 


\subsection{Result of Topology Optimization}

The optimisation results are shown in Figures 11 and 12. The simulation used elements with $\rho>0.5$. The material is removed from the part that is not too much affected by the force applied in order to obtain the lighter bucket tooth with similar stress level. In the results of design optimization variable 2 experienced a slight increase in the maximum voltage Von Mises but was still below $5 \%$ so it was still acceptable.

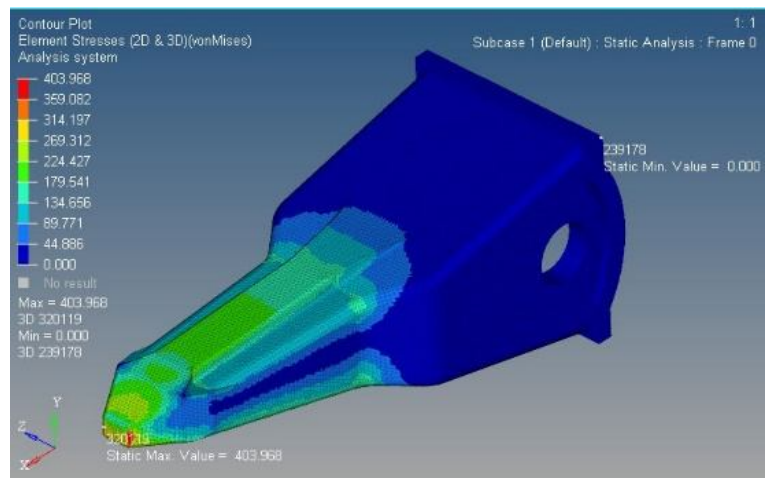

Figure 9: Von Mises value of convergent test 4.

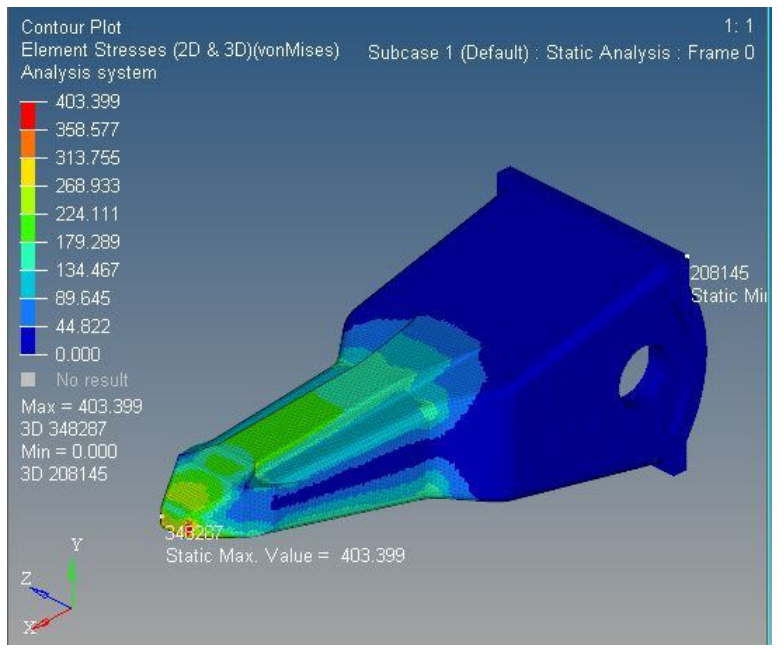

Figure 10: Von Mises value of convergent test 5.

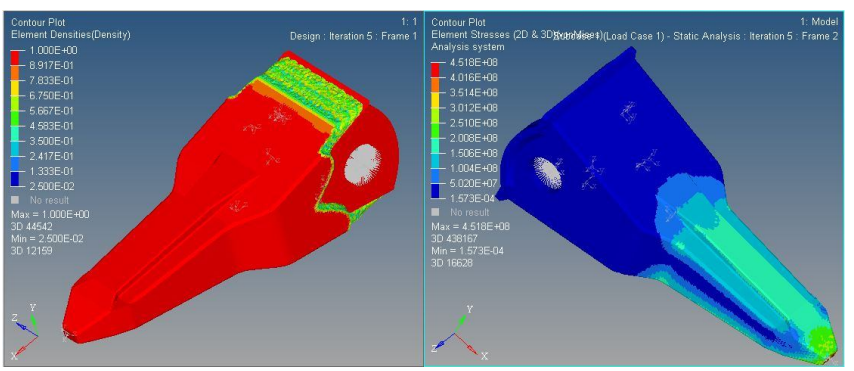

Figure 11: Results of optimization of variable design topology 1.

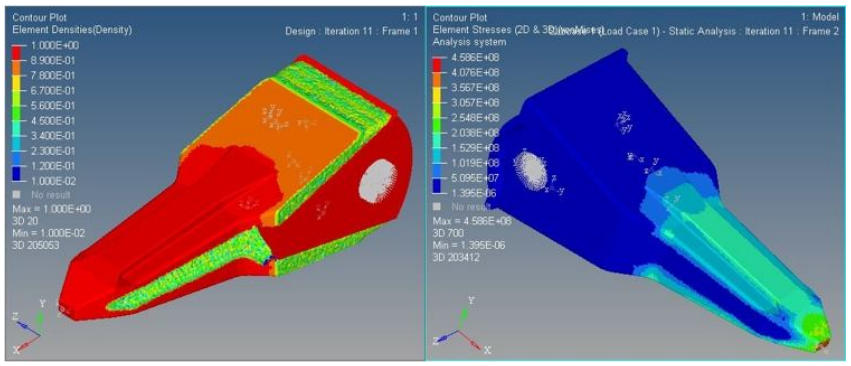

Figure 12: Results of optimization of variable design topology 2.

The optimization results above can be known computationally through weight compliance graphs on the optimization results of variable 1 design with variable 2 design shown in Figure 13 and Figure 14.

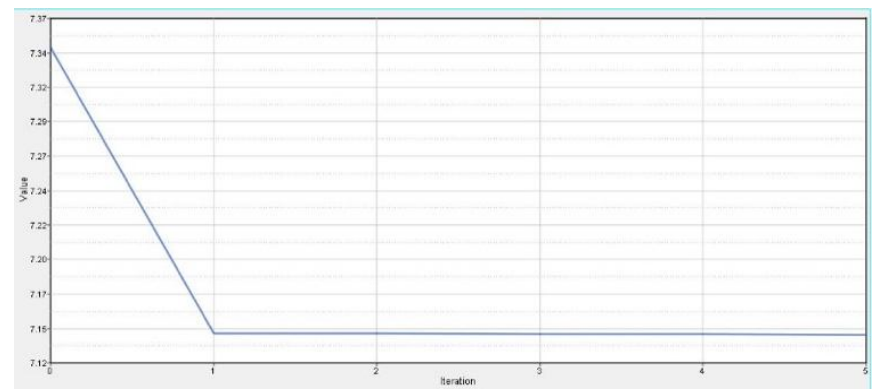

Figure 13: Graph of design variable compliance value 1.

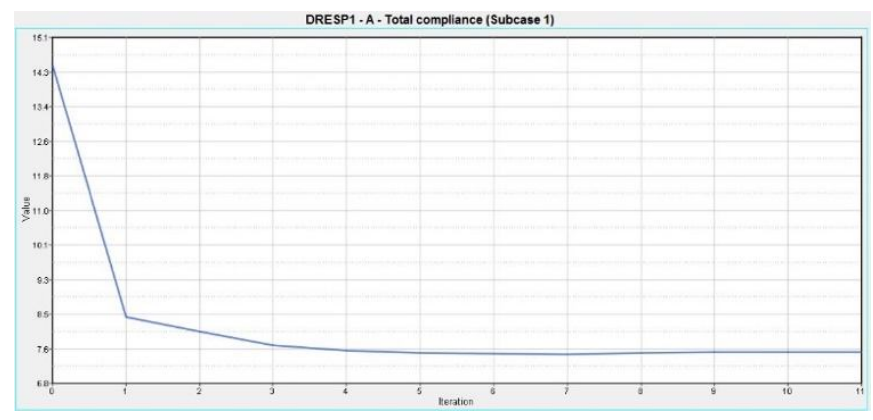

Figure 14: Graph of design variable compliance value 2.

\subsection{Discussion of Topology Optimization Result}

Topology optimization is one form of optimization that is often applied to a structure' The application of topology optimization in this study aims to change the design of the Verona PC200 bucket tooth into a lighter design. The approach used is the density distribution method or SIMP method which changes the structure of the bucket tooth continuum into a discrete structure in the form of elements [12]. This method can produce a bucket tooth design that is lighter and optimal. This is indicated by the comparison of the results of design optimization between the initial design and the design after optimization in the following Table 3. 
Sumar Hadi Suryo et al., International Journal of Emerging Trends in Engineering Research, 8(6), June 2020, 2426 - 2430

Table 3: Comparison of initial design and after optimization.

\begin{tabular}{|c|c|c|}
\hline Comparison & $\begin{array}{c}\text { Design } \\
\text { Variable 1 }\end{array}$ & Design Variable 2 \\
\hline Initial Mass & $6.25 \mathrm{~kg}$ & $6.25 \mathrm{~kg}$ \\
\hline $\begin{array}{c}\text { Mass after } \\
\text { Optimization }\end{array}$ & $5.53 \mathrm{~kg}$ & $4.97 \mathrm{~kg}$ \\
\hline $\begin{array}{c}\text { Initial Maximum } \\
\text { Stress }\end{array}$ & $403.31 \mathrm{MPa}$ & $403.31 \mathrm{MPa}$ \\
\hline $\begin{array}{c}\text { Maximum Stress } \\
\text { after Optimization }\end{array}$ & $451.8 \mathrm{MPa}$ & $458.6 \mathrm{MPa}$ \\
\hline Initial Safety Factor & 3.75 & 3.75 \\
\hline Final Safety Factor & 3.35 & 3.30 \\
\hline
\end{tabular}

\section{CONCLUSION}

Based on the results of the research that has been carried out, it can be concluded that after static linear simulations using the finite element method, a maximum of $403.81 \mathrm{MPa}$ of Von Mises stress is obtained. From the topology optimisation results obtained a decrease in mass in the design of the first variable of $0.72 \mathrm{~kg}$ and on the design of variable 2 of $1.49 \mathrm{~kg}$.

Also, the maximum Von Mises stress in variation 1 increased to $451.8 \mathrm{MPa}$, whereas in variation 2 it was $458.6 \mathrm{MPa}$. As a result of the increase in the voltage makes the value of the safety factor of the design of the first variable worth 3.35 and the second variable design value of 3.30 which can be said the value of the voltage that occurs in both designs although it tends to rise but is still declared safe. When compared between the two results of optimisation of the two designs that the most optimal aspect of wear-life is the result of the variation of the first design variable, while the optimisation aspect of compliance is the result of the variation of the second design variable.

\section{REFERENCES}

1. B.P. Shaik. Analysis of Bucket Teeth of Backhoe Excavator Loader and its Weight Optimization, International Journal of Engineering Research \& Technology, 4(5), 289-295, 2015. https://doi.org/10.17577/IJERTV4IS050402

2. J.E. Fernandez, R. Vijande, R. Tucho, J. Rodriguez, A. Martin. Materials selection to excavator tooth in mining industry, Wear, 250(1-12), 11-18, 2001.
https://doi.org/10.1016/S0043-1648(01)00624-X

3. Altair HyperWorks Help, 2015. Available: http://www.altairhyperworks.com/hwhelp/Altair/hw12. 0/index.aspx

4. Altair Optimization Guide Book. Practical Aspect of Structure Optimization, 2015.

5. M.P. Bendsøe, O. Sigmund. Topology Optimization Theory Methods and Applications; Berlin Heidelberg, Germany: Springer-Verlag, 2003, ISBN 3-540-42992-1.

6. A.E. Ismail, Stress Intensity Factors of Cracks in Solid Cylindrical Bars using ANSYS Finite Element Analysis, International Journal of Emerging Trends in Engineering Research, 8(4), 1395-1404, 2020. https://doi.org/10.30534/ijeter/2020/74842020

7. H.Y. Tan, K. S. Basaruddin, S. F. Khan, M.H. Mat Som and A. R. Sulaiman, Performance Evaluation of Polygon-based and Voxel-based Finite Element Analysis on Tibia with Osteogenesis Imperfecta, International Journal of Emerging Trends in Engineering Research, 7(11), 695 - 699, 2019. https://doi.org/10.30534/ijeter/2019/467112019

8. E. Julianto, W.A. Siswanto, M. Effendy, Characteristics of Temperature changes and Stress of Float Glass under Heat Radiation, International Journal of Emerging Trends in Engineering Research, 7(9), 228-233, 2019.

https://doi.org/10.30534/ijeter/2019/03792019

9. SAE International, SAE J1179; Hydraulic Excavator and Backhoe Digging Force. Warrendale : SAE, 1990.

10. K.S. Dagwar, R.G. Telrandhe. Failure Analysis of Excavator Bucket Tooth, International Journal of Scientific Research and Engineering Studies, 4, 2349-8862, 2015.

11. E. Oñate. Structural Analysis with the Finite Element Method, Lecture Notes on Numerical Methods in Engineering and Sciences; Barcelona: Artes Gráficas Torres S.A., 2003.

12. Christensen, P.W., Klarbring, A. An Introduction to Structural Optimization; Berlin Heidelberg, Germany: Springer-Verlag, 2008, ISBN-13: 978- 1402086656. 